\title{
Clinical Case Studies in Neurolinguistics and Language Pathology
}

\section{Stavroula Stavrakaki*}

Aristotle University of Thessaloniki, Greece

Neurolinguistics is mainly concerned with the study of language production and comprehension in relation to the brain structures and functions. A central topic in this scientific discipline is the study of language disorders especially those caused by brain damage (for an introduction in the field, see, Ahlsén [1], Ingram [5], Obler \& Gjerlow [10]).

Indeed, the emergence of the scientific discipline of neurolinguistics is traced in the $19^{\text {th }}$ century and strongly related to the case studies of patients who suffered a stroke. These studies were carried out by early 'aphasiologists', who investigated the effect of brain damage on language (Ahlsén [1], Caplan [3], Obler \& Gjerlow [10], Whitaker [14]). Paul Broca [2] reported the case of a famous patient known in the literature as 'Tan' apparently because 'tan' was the only syllable he could produce despite his normal comprehension abilities. This patient suffered a lesion in the third frontal gyrus in the left hemisphere. This area has been known as 'Broca's area'. Based on this evidence, Paul Broca argued in favor of the localization view of language processing, which considers the language function to be connected with particular brain centers. Clinical case studies dominated the aphasiology investigations in the $19^{\text {th }}$ century and raised the question of localization of language, as pointed out by many investigators of the neurolignuistics history (see for example, Whitaker [14], for a more recent review, see Ahlsén [1]).

Notably, the research line originated in Broca's [2] report has strongly influenced the adult neuropsychology research and especially a particular approach called 'classical neuropsychology', as mentioned by Temple [11]. The researchers following that approach seek to connect specific brain lesions with certain behavioral patterns as exactly the early 'aphasiologists' of the $19^{\text {th }}$ century did. However, as Temple [11] notes, in contrast to the early 'aphasiologists', these researchers do not work anymore with case studies but employ group of patients who suffered a lesion in the same brain area.

In addition to the classical neuropsychology approach, Temple [11] points out that there is a more recent approach known as 'cognitive neuropsychology'. Researchers working within this framework aim at providing accounts of typical cognitive function while explaining the patterns of impaired performance of patients (see Temple [11], and references therein). Case studies have been considered as the most fruitful method to investigate the cognitive functions in patients with neurological damage mainly due to the widely attested individual differences among patients. This is so because, as Temple [11] points out, 'averaging across subjects might mask the most relevant aspect of performance'. In addition, she underlines the clinical significance of the case studies, as it is possible in this way to illuminate how the patient's performance changes over time.

A significant variable that could contribute to behavioral changes in patients is related to the therapy type these patients are exposed. As a consequence, a considerable amount of research in current aphasiology deals with single case studies of patients exposed to a specific type of treatment and explores the outcomes of this treatment. Given that difficulties with verbs and sentence production and/or comprehension are widely attested in patients with aphasia (see Hickok \& Avrutin [4], McAllister et al. [7], among many others) a significant number of therapy studies were designed to evaluate the effectiveness of the intervention programmes employed for these patients. A keynote question is whether the intervention at the level of verb or verb argument structure can result in improvement at the sentential level. This therapeutic question is theoretically driven (see, Webster \& Gordon, [12]), as in the Levelt's [6] psycholinguistic model of speech production verb lemmas are associated to the sentence syntax in the following way: The verb lemmas, which contain the semantic and grammatical information are accessed by the grammatical encoder, which produces the sentence surface structure. It is, thus under investigation whether intervention targeted at the level of verb naming and semantics could improve the patients' performance on sentence production and/or comprehension. The results of these studies appear to be quite conflicting as some of them show that intervention at the level of verb naming does not improve sentence production (Mitchum \& Berndt [9], for a review, Webster \& Gordon [12]) while others show apparent benefits at the sentence level (Marshall et al. [8] for a review, Webster \& Gordon [12]). By contrast, intervention targeting verb argument structure through developing the patient's awareness of the verb-noun connection seems to be more effective than therapy targeting single verb naming without any intervention at the level of argument structure (Webster et al. [13], Webster \& Gordon [12]). In sum, while generalizations cannot be easily made on the basis of single case reports, multiple case studies in the domain of speech and language intervention can show that some therapeutic approaches are more effective than others. In this respect, clinical case studies in the field of language intervention for patients with lesions contribute to the improvement of therapeutic programmes employed for these patients.

Concluding, clinical cases studies of patients still remain necessary and important in the field of neurolinguistics and language pathology.

\section{References}

1. Ahlsén E (2006) Introduction to Neurolinguistics. Amsterdam/Philadelphia: John Benjamins.

2. Broca $P$ (1861) Remarques sur le siege de la faculte de la parole articulee, suivies d' une observation d' aphemie (perte de parole). Bulletin de la Societe d' Anatatomie (Paris) 36: 330-357.

3. Caplan D (1987) Neurolinguistics and linguistic aphasiology: An introduction Cambridge: Cambridge University Press.

4. Hickock G, Avrutin S (1995) Representation, Referentiality and Processing in

*Corresponding author: Stavroula Stavrakaki, Aristotle University of Thessaloniki, Greece, E-mail: svoula@auth.gr

Received January 02, 2012; Accepted January 07, 2012; Published January 13 2012

Citation: Stavrakaki S (2012) Clinical Case Studies in Neurolinguistics and Language Pathology. J Clinic Case Reports 2:e109. doi:10.4172/2165-7920.1000e109

Copyright: @ 2012 Stavrakaki S. This is an open-access article distributed under the terms of the Creative Commons Attribution License, which permits unrestricted use, distribution, and reproduction in any medium, provided the original author and source are credited. 
Citation: Stavrakaki S (2012) Clinical Case Studies in Neurolinguistics and Language Pathology. J Clinic Case Reports 2:e109. doi:10.4172/2165$7920.1000 \mathrm{e} 109$

Agrammatic Comprehension: Two case studies. Brain and Language 50: 1026.

5. Ingram J (2007) Neurolinguisitcs. An introduction to spoken language processing and its disorders. Cambridge: Cambridge University Press.

6. Levelt WJM (1989) Speaking. From intention to articulation. Cambridge, MA The MIT Press.

7. McAllister T, Bachrach A, Waters G, Michaud J, Caplan D (2009) Production and comprehension of unaccusatives in aphasia. Aphasiology 23: 989-1004.

8. Marshall J, Pring T, Chiat S (1998) Verb retrieval and sentence production in aphasia. Brain Lang 63: 159-183.

9. Mitchum CC, Berndt RS (1994) Verb retrieval and sentence construction: Effects of targeted intervention. In: Riddoch MJ and Humphreys GW (Eds.), Cognitive Neuropsychology and Cognitive Rehabilitation. Hove: Lawrence Erlbaum.
10. Obler LK, Gjerlow K (1999) Language and the Brain. Cambridge: Cambridge University Press.

11. Temple C (1997) Developmental Cognitive Neuropsycholgy. Hove, Eas Sussex: Psychology Press.

12. Webster J, Gordon B (2009) Contrasting therapy effects for verb and sentence processing difficulties: A discussion of what worked and why. Aphasiology 10 : 1231-1251.

13. Webster J, Morris J, Franklin S (2005) Effects of therapy targeted at verb retrieval and the realisation of the predicate argument structure: A case study Aphasiology 19: 748-764.

14. Whitaker H (1998) History of Neurolinguistics. In: B Stemmer \& H Whitake (Eds.), The Handbook of Neurolinguistics, pp. 27-49. San Diego and London: Academic Press. 